\title{
Exploring Influences of Sport Experiences on Social Skills in Physical Education Classes in College Students
}

\author{
Jiandong Ding, Yoshio Sugiyama \\ Faculty of Human-Environment Studies, Kyushu University, Fukuoka, Japan \\ Email: djd19810716@yahoo.co.jp
}

How to cite this paper: Ding, J. D. \& Sugiyama, Y. (2017). Exploring Influences of Sport Experiences on Social Skills in Physical Education Classes in College Students. Advances in Physical Education, 7, 248259.

https://doi.org/10.4236/ape.2017.73020

Received: May 11, 2017

Accepted: July 15, 2017

Published: July 18, 2017

Copyright () 2017 by authors and Scientific Research Publishing Inc. This work is licensed under the Creative Commons Attribution International License (CC BY 4.0).

http://creativecommons.org/licenses/by/4.0/

\begin{abstract}
This study investigated the influences of sport experiences on social skills among Chinese college students in physical education (PE) classes. First, we tested the reliability and validity of the Chinese version of the Experience Scale in University Physical Education Classes (ESUPEC) for examining Chinese college students' sport experiences in PE classes. Students $(n=366,194$ males, 172 females, mean age $=18.6$ years) from two universities in China completed a survey using the Chinese version of ESUPEC. Results of factor analyses and reliability analyses indicated that the structure of the scale was consistent with the original version of ESUPEC, and the reliability and validity of the scale were reasonable well. Then, we administered the Chinese version of ESUPEC and the 11 item of Social Skills Inventory (11-SSI) to 302 freshmen (157 males, 145 females) to examine their sport experiences and social skills in PE classes. Results of correlation analysis and regression analysis revealed that male students' sport experiences that involved challenge and female students' sport experiences that involved self-disclosure had a positive influence on their nonverbal skills; female students' sport experiences that involved enjoyment had a positive influence on their verbal skills. The study contributes to literature on exploring how college students' social skills can be developed through learning in PE. The work of the study made a step to provide educators with methods for effective development and efficient implementation of models and programs in PE classes.
\end{abstract}

\section{Keywords}

Sport Experiences, College Students, Nonverbal Skills, Verbal Skills, Physical Education Classes, Development

\section{Introduction}

PE class has been recognized as an ideal environment in school to develop stu- 
dents' social skills (Eldar, Morris, DaCosta, \& Wolf, 2006; González, Regalado, \& Guerrero, 2010). PE curriculum offers specific opportunities, which are not available in other curriculum areas (Laker, 2000; Siedentop, 1991), for the practice of sportsmanship, courtesy, and their concomitants in social behaviors (Duncan \& Watson, 1960). Therefore, there may be certain factors that contribute to students' social skills development in the complex context of PE. In recent years, sport pedagogy towards PE has witnessed the development of a growing number of models and programs, for example, Metzler (2011) identified eight different instructional models that are commonly implemented in PE today (e.g., cooperative learning \& sport education). To date, considerable interests have been shown in applying instructional models and their hybridizations in PE to promote students' social skills. However, despite model-based programs and strategies, little attention has been paid to explore factors that can influence students' social skills, or explain how students' social skills can be improved during the learning process in PE. For effective development and efficient implementation of models and programs, it is necessary to study in this field.

Students learn social behaviors in PE through sport and physical activities. PE maximizes opportunities for students to experience a somewhat parallel festive nature of sport (Bennett \& Hastie, 1997), and it provides opportunities for students to experience both objectionable and desirable forms of behaving. PE classes that implement instructional models can provide students with meaningful sport experiences (Hannon \& Ratliffe, 2004; Siedentop, Hastie, \& van der Mars, 2004; Slentz \& Chase, 2003). Sport experience obtained by physical movement facilitates personal attributes and guides life values, interests, and careers (Fraser-Thomas \& Cote, 2009). Positive sport experiences may provide a psychologically safe environment where individuals are willing to take risks and learn from their mistakes (Danish, Petitpas, \& Hale, 1993), and these experiences may become what Zimmerman (1990) in the theory of Learned Hopefulness called "empowering experiences", which provide opportunities to learn skills and help individuals cope with stress and solve problems when living socially with others (Smith \& Karp, 1997). In recent years, there have been growing interests to examine the effects of sport experiences on students' social development. A study conducted by Shimamoto and Ishii (2007) revealed that the sport experiences that involved self-disclosure had a positive influence on both male and female college students' life skills. Sugiyama (2012) in his study found that students' improvement of certain types of nonverbal skills could be influenced by their sport experiences in PE classes. However, studies in this field are still developing, especially in China. Students' social skills acquired through learning in PE classes may be different from those they use in daily life (Ding \& Sugiyama, 2016). Adult behavior patterns are established and strongly influenced during the late adolescent and college years (Dishman \& Dunn, 1988; Pearman \& Valois, 1997). As we know, no study was conducted to examine the effects of college students' sport experiences on their social skills in PE classes. Therefore, the purpose of this study was to examine the influences of college students' sport 
experiences on their social skills in PE classes through validating an instrument that can be used to evaluate Chinese college students' sport experiences in PE classes. It was expected that this study will contribute to efforts to explore factors that influence college students' social skills, and provide educators with methods for effective development and efficient implementation of models and programs in PE classes.

\section{Methods}

\subsection{Instruments}

\subsubsection{1-SSI}

Students' social assets or competencies are those behaviors that can be learned in one domain (e.g., sports) and generalized or transferred to other domains (e.g., school, family, \& community) (Maureen, Nicole, \& Lindsay, 2014). The social skills students acquire in a PE setting may be different from the social skills they use in their daily lives (Sugiyama et al., 2010). Therefore, it is necessary to exert cautions when choosing instruments to evaluate the improvement of social skills. Riggio's $(1986,1989)$ Social Skills Inventory (SSI) is a standardized and representative instrument that was designed to assess certain key dimensions of adults' social skills in daily life. By considering the process of skills transfer, Ding and Sugiyama (2016) distinguished the social skills that were acquired during PE from those that were used in daily life, and developed the 11-SSI to assess Chinese college students' social skills in PE classes. The items included in the measure were selected from Riggio's SSI and were revised based on the unique contexts of PE and native Chinese culture. The 11-SSI has 11 items, including those concerning basic communication skills, and the items are distributed across two subscales, namely, verbal skills (five items) and nonverbal skills (six items). Each item has to be answered on a 5-point Likert scale ranging from "not at all like me" to "exactly like me", and the scores on the subscales range from 11 to 55 .

\subsubsection{Chinese Version of ESUPEC}

ESUPEC is a Japanese version developed by Shimamoto and Ishii (2007). It consists of 14 items in 4 subscales which are self-disclosure (four items), that is "expressing one's mind to others in sport activities", cooperation (four items), that is "working together to reach goals in sport activities", challenge (three items), that is "achieving success that they had never got before in sport activities", and enjoyment (three items) which means "perceiving fun and pleasure in sport activities". Each item has to be answered on a 4-point Likert scale ranging from "none" to "often have". In this study, the translation of the ESUPEC into Chinese version was conducted by three Chinese master course students who had been studying in Japan as foreign students for over four years. They were all in Japanese language major during university years and had passed the Japanese Language Proficiency Test of level 1.

\subsection{Participants and Procedures}

We carried out two surveys in this study. College students of two universities in 
two cities (i.e., Dalian \& Sanya) in China were investigated. In the first survey, the Chinese version of ESUPEC was administered to a sample of 366 students that included 194 students at the university in Dalian and 172 students at the university in Sanya. Students at the university in Dalian are 100 freshmen (55 males, 45 females) and 94 sophomores (50 males, 44 females); students at the university in Sanya are 89 freshmen (46 males, 43 females) and 83 sophomores (43males, 40 females). Forty freshmen ( 23 males, 17 females) at the university in Dalian retook the questionnaire two weeks after the initial administration. The data of the first survey was used to test the reliability and validity of the Chinese version of ESUPEC for examining Chinese college students' sport experiences in PE classes. In the second survey, the Chinese version of ESUPEC and the 11-SSI were administered to a sample of 302 freshmen who had been studying in the school for only one month. The sample included 155 students $(81$ males, 74 females) at the university in Dalian and 147 students (76 males, 71 females) at the university in Sanya. The data of the second survey was used to assess the influences of sport experiences on social skills in PE classes. The surveys of this study were carried out after we had received permissions of investigation as well as agreements of assistance from the chairs of the PE department of the two universities. We posted questionnaires to the two PE departments, and then the two chairs called for teachers to administer the questionnaires. The second survey was conducted three months later after the first survey. Questionnaires of the two surveys were returned to us also by post after each administration.

\subsection{Analysis Means}

We performed exploratory factor analysis to examine factor components of the Chinese version of ESUPEC. We verified the reliability of the scales by calculating Cronbach's $a$ coefficient and the test-retest correlation coefficient $r$. We used confirmatory factor analysis to determine the validity of the scale. Correlation analyses were performed to examine whether there were relationships between students' social skills and sport experiences. Multiple regression analyses were performed to assess the influences of students' sport experiences on their social skills. We performed data analysis by using SPSS 22.0 and Amos 22.0 for Windows.

\section{Results}

\subsection{Factor Components of the Chinese Version of ESUPEC}

The Chinese version of ESUPEC was translated from the original Japanese version of ESUPEC. Due to the differences in subjects, PE curriculum, and social culture between the two countries, it was necessary to examine whether the items in Chinese version were in accordance with the items in original version in testing distinct aspects of sport experience. Therefore, we performed an exploratory factor analysis by using principal component method with varimax rotation, on the sample $(n=366)$ of the first survey. Bartlett's test of sphericity (1633.098) and KMO (0.851) suggested the necessity and feasibility of conducting factor 
analysis. Result (Table 1) of the analysis revealed 4 factors of which eigenvalues were all above 1.0. Factor components were consistent with the original version of which the items were located on 4 factors, namely, self-disclosure, cooperation, challenge, and enjoyment.

\subsection{Reliability and Validity of the Chinese Version of ESUPEC}

We calculated Cronbach's $\alpha$ coefficient, which is a reliability index of internal consistency, to assess the reliability of the Chinese version of ESUPEC. The reliability coefficient $\alpha$ of the total scale was 0.864 and those of the subscales were ranging from 0.688 to 0.860 . In addition, we conducted a correlation analysis for the two-week test-retest. The correlation coefficient $r$ for the total skills was 0.928 , and those for the subscales were ranging from 0.911 to 0.934 (Table 2). Thus, the results verified that the scale was reliable in evaluating Chinese college students' sport experiences in PE classes.

We performed a confirmatory factor analysis to assess the validity of factor component of the Chinese version of ESUPEC in evaluating sport experiences in

Table 1. Result of the exploratory factor analysis of the Chinese version of ESUPEC ( $n$ =366).

\begin{tabular}{|c|c|c|c|c|c|c|}
\hline \multirow{2}{*}{ Items } & \multirow{2}{*}{ Mean } & \multirow{2}{*}{ SD } & \multicolumn{4}{|c|}{ Factor loadings } \\
\hline & & & 1 & 2 & 3 & 4 \\
\hline \multicolumn{7}{|l|}{ Self-disclosure } \\
\hline I had expressed my feelings to others & 2.574 & 0.812 & 0.742 & & & \\
\hline I had communicated my ideas to friends & 2.845 & 0.786 & 0.820 & & & \\
\hline I had talked to someone about personal things & 2.755 & 0.863 & 0.801 & & & \\
\hline Someone had often listened my words & 2.874 & 0.844 & 0.726 & & & \\
\hline \multicolumn{7}{|l|}{ Cooperation } \\
\hline I had been in teamwork & 3.213 & 0.818 & & 0.759 & & \\
\hline I had coordinated with teammate to play & 3.004 & 0.759 & & 0.831 & & \\
\hline I had cooperated with many people during play & 3.032 & 0.791 & & 0.851 & & \\
\hline Teammates had encouraged each other & 3.134 & 0.747 & & 0.674 & & \\
\hline \multicolumn{7}{|l|}{ Challenge } \\
\hline $\begin{array}{l}\text { I had succeeded in challenging what } \\
\text { was impossible to me }\end{array}$ & 2.733 & 0.804 & & & 0.753 & \\
\hline $\begin{array}{l}\text { I had succeeded in challenging what was } \\
\text { difficult to me }\end{array}$ & 2.516 & 0.810 & & & 0.824 & \\
\hline $\begin{array}{l}\text { I had succeeded in challenging what I } \\
\text { had never done }\end{array}$ & 2.365 & 0.893 & & & 0.751 & \\
\hline \multicolumn{7}{|l|}{ Enjoyment } \\
\hline I had played in a harmonious class context & 3.292 & 0.750 & & & & 0.849 \\
\hline I had played in a relaxed way & 3.321 & 0.743 & & & & 0.819 \\
\hline I had played games and done free practices & 2.816 & 0.896 & & & & 0.530 \\
\hline Eigenvalues & & & 2.814 & 2.596 & 2.218 & 1.931 \\
\hline Variance explained (\%) & & & 20.103 & 18.540 & 15.843 & 13.791 \\
\hline
\end{tabular}


Table 2. Coefficients of internal consistency $\alpha$ and test-retest correlation $r$ for the Chinese version of ESUPEC.

\begin{tabular}{ccc}
\hline & Cronbach's $\alpha$ & Test-retest $r$ \\
\hline Self-disclosure & 0.808 & $0.926^{* *}$ \\
Cooperation & 0.860 & $0.917^{* *}$ \\
Challenge & 0.773 & $0.911^{\star *}$ \\
Enjoyment & 0.688 & $0.934^{* *}$ \\
Total sport experience & 0.864 & $0.928^{* *}$ \\
\hline
\end{tabular}

${ }^{* *} p<0.01$.

PE classes (Figure 1). The Goodness of Fit Index (GFI) was 0.924. The Adjusted Goodness of Fit Index (AGFI) was 0.888. The Comparative Fit Index (CFI) was 0.945. The Root Mean Square Error of Approximation (RMSEA) was 0.067. The result suggested that the hypothesized four-factor model developed based on the result of exploratory factor analysis fits the data reasonably well.

\subsection{Results of Correlation Analyses}

In order to determine whether there were relationships between college students' social skills and sport experiences in PE classes, we performed correlation analyses separately on male samples $(n=157)$ and female samples $(n=145)$ of the second survey. Results (Table 3 ) showed that sport experiences had a significant correlation with nonverbal skills in both male students $(r=0.447, p<0.001)$ and female students $(r=0.217, p<0.01)$. However, no significant correlation was found between sport experiences and verbal skills either in male students or in female students.

\subsection{Influences of Sport Experiences on Social Skills}

In order to determine whether various sport experience have an influence on college students' social skills in PE classes, we performed multiple regression analyses separately on male samples $(n=157)$ and female samples $(n=145)$ of the second survey. First, collinearity diagnostics indicated that the collinearity for variables of sport experience in each sample was weak (VIF $=1.221-1.755$ ). Then, four aspects of sport experience (i.e., self-disclosure, cooperation, challenge, \& enjoyment) were entered to regress on each sample's verbal skills and nonverbal skills. Results (Table 4) showed that the $R^{2}$ of the regression equation in which sport experiences were regressed on nonverbal skills reached the significant level both in male students $\left(R^{2}=0.328, p<0.001\right)$ and female students $\left(R^{2}=0.110, p<0.01\right)$. It is indicated that sport experiences had a strong influence on nonverbal skills in all students. Of the four aspects of sport experience, self-disclosure was found to have a positive and significant influence on female students' nonverbal skills $(\beta=0.318, t=3.613, p<0.001)$; challenge was found to have a positive and significant influence on male students' nonverbal skills ( $\beta$ $=0.490, t=3.733, p<0.001)$; enjoyment was found to have a positive and sig- 


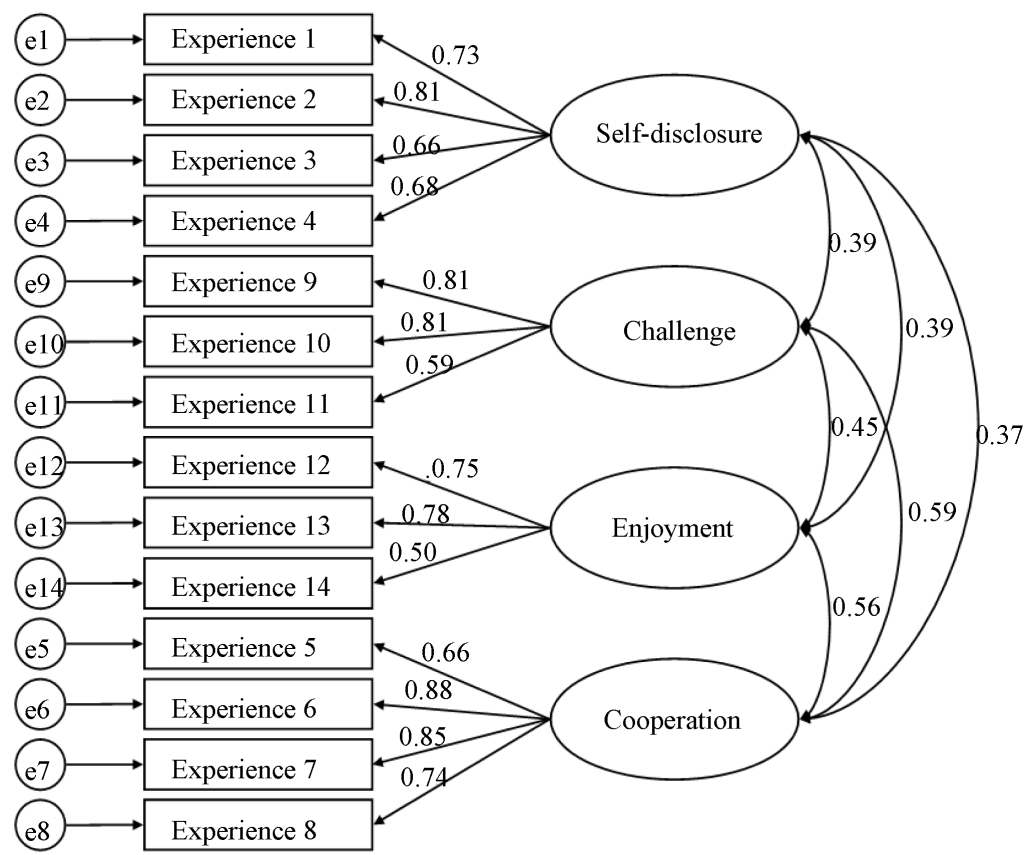

Figure 1. Result of the confirmatory factor analysis of the Chinese version of ESUPEC.

Table 3. Total sport experience in relation to verbal skills and nonverbal skills in male sample and female sample.

\begin{tabular}{ccc}
\hline & \multicolumn{2}{c}{ Total sport experience } \\
\cline { 2 - 3 } & Male $(n=157)$ & Female $(n=145)$ \\
\hline Verbal skills & -0.006 & 0.030 \\
Nonverbal skills & $0.447^{* * *}$ & $0.217^{* *}$ \\
\hline
\end{tabular}

${ }^{* *} p<0.01,{ }^{* *} p<0.001$.

Table 4. Regression models of sport experiences in relation to verbal skills and nonverbal skills in male sample and female sample.

\begin{tabular}{|c|c|c|c|c|c|c|c|c|}
\hline & \multicolumn{4}{|c|}{ Verbal skills ${ }^{\mathrm{a}}$} & \multicolumn{4}{|c|}{ Nonverbal skills ${ }^{\mathrm{a}}$} \\
\hline & $\beta$ & $S E$ & $t$ & $R^{2}$ & $\beta$ & $S E$ & $t$ & $R^{2}$ \\
\hline \multicolumn{9}{|l|}{ Male $(n=157)$} \\
\hline Self-disclosure & 0.039 & 0.188 & 0.276 & & 0.173 & 0.180 & 1.479 & \\
\hline Cooperation & -0.098 & 0.227 & -0.623 & & -0.249 & 0.217 & -1.887 & \\
\hline Challenge & -0.159 & 0.282 & -1.009 & & 0.490 & 0.271 & $3.733^{* * *}$ & \\
\hline \multirow[t]{2}{*}{ Enjoyment } & 0.215 & 0.288 & 1.365 & & 0.162 & 0.276 & 1.235 & \\
\hline & & & & 0.038 & & & & $0.328^{* * *}$ \\
\hline \multicolumn{9}{|l|}{ Female $(n=145)$} \\
\hline Self-disclosure & -0.145 & 0.129 & -1.594 & & 0.318 & 0.123 & $3.613^{\star * *}$ & \\
\hline Cooperation & -0.027 & 0.147 & -0.225 & & 0.038 & 0.139 & 0.364 & \\
\hline Challenge & 0.020 & 0.165 & 0.202 & & 0.034 & 0.157 & 0.365 & \\
\hline \multirow[t]{2}{*}{ Enjoyment } & 0.211 & 0.181 & $2.255^{*}$ & & -0.088 & 0.171 & -0.966 & \\
\hline & & & & 0.051 & & & & $0.110^{* *}$ \\
\hline
\end{tabular}

${ }^{a}$ Dependent variable. ${ }^{*} p<0.05,{ }^{* *} p<0.01,{ }^{* *} p<0.001$. 
nificant influence on female students' verbal skills $(\beta=0.221, t=2.255, p<$ 0.05).

\section{Discussion}

\subsection{Implications}

The current study assessed the influences of college students' sport experiences on their social skills in PE classes through validating the Chinese version of ESUPEC. The Chinese version of ESUPEC was explored to have the same factor structure with the original Japanese version, and demonstrated to have reasonable internal consistency reliability and factorial validity. It means that despite the differences in students and PE curriculum between the two countries (i.e., China \& Japan), the ESUPEC could be a common instrument in evaluating college students' sport experiences in PE classes. Through conducting correlation analyses, we examined relationships between students' sport experiences and their social skills. The findings provided the basis for the current study to explore the effects of sport experiences on social skills in PE classes. In this study, college students' sport experiences were found to have a positive influence on their nonverbal skills. However, the significant influences were from different aspects of sport experience among male and female students. Challenge, which means "achieving success that a person had never got before in sport activities", was found to have a significant influence on male students' nonverbal skills. PE provides an environment for students to join sport activities in which they can consciously seek out and test their abilities against what they perceive as a more challenging competition. People can gain confidence from overcoming obstacles or challenges and can be motivated to persist at an activity (Bandura, 1997). Male students are more active and competitive than female students to overcome challenges in sport activities. Therefore, if PE curriculums contain various sport activities in which students can successfully challenge what they had never done before, male students' nonverbal skills will possibly be promoted through learning in the classes. PE can provide challenges for students toward self (e.g., breaking a running record), objects (e.g., learning a football skill), and environment (e.g., completing an orienteering) (Kang \& You, 2003). Researchers and educators may use these challenges in their models or programs in the PE curriculum for the development of students' nonverbal skills, especially in male students. Self-disclosure, which means "expressing one's mind to others in sport activities", was found to have a significant influence on female students' nonverbal skills. The ability to reveal one's thoughts and feelings to others is a basic social skill for developing interpersonal relationships (Altman \& Taylor, 1973). Female students tend to disclose more than male students, and they are more frequently the recipients of other's disclosure as well (Dolgin \& Minowa, 1997). Thus, if more opportunities are provided to students to disclose their information to others in PE classes, female students will more possibly have the benefit of their nonverbal skills development. Students show higher self-disclosure to their best friends of same sex than others (Enomoto, 1987). In order to develop female 
students' nonverbal skills, teachers may lead them to choose their group members themselves when organizing group learning or cooperative games in PE classes. Besides, as teachers' communication behaviors could influence students' willingness of self-disclosure (Anita, Karen, \& Mark, 1977), they should take care of their actions when teaching PE. In this study, enjoyment, which means "perceiving fun and pleasure in sports activities", was found to have a significant influence on female students' verbal skills. Sport enjoyment was associated with satisfaction of motor performance and higher degrees of perceived physical challenge and competence (Boyd \& Yin, 1996; Brustad, 1988). Therefore, teachers should take consideration on the physical activity level when teaching female students in PE for the development of their verbal skills. Teachers should also take care of their behaviors as it has been demonstrated by studies (Cai, 1998; Cecchini et al., 2001; Hashim, Grove, \& Whipp, 2008) that their actions were positively associated with students' enjoyment in PE.

\subsection{Limitations}

There are limitations in this study. First, students' sport experiences discussed in this study are not inclusive. PE class environment is particularly complex, and sport activities in PE are complicated processes in which students experience multiple changes of their physical and psychosocial status. Therefore, there may be other sport experiences that directly or indirectly affect students' social skills. An effort has been made in this study to assess the impact of sport experiences on students' social skills in PE classes; however, further research in this field need to be conducted to explore the contribution of other sport experiences to social skills development. Second, many studies had demonstrated that cooperative learning in PE contributed to students' social development. However, in this study, no significant and direct influence of cooperation on social skills was found. As cooperative learning through sport activities can provide students with enjoyment, and teambuilding activities which in turn encourages cooperation in PE emphasizing on participation, challenge, and fun (Gruno \& Gibbons, 2013), further studies need to examine whether cooperation has an indirect influence on students' social skills by way of influencing challenge, enjoyment, or other sport experiences.

\section{Conclusion}

Different aspects of sport experience were found to effect different social skills depending on the gender. This study made an effort for exploring how students' social skills can be developed through learning in PE. Sport experience was demonstrated to be a method and manner to promote students' social skills in PE classes. PE lessons should be structured in ways that students have the opportunities to achieve successes in challenging their physical competence, express their psychosocial sense to their peers, and experience pleasure and satisfaction through motor accomplishments and interactions with other students. The findings of the study contribute to effective development and efficient im- 
plementation of models and programs, and provide policy makers with suggestions on curriculum modification and teacher professional training. However, further studies still need to be conducted to examine the influences of various sport experience as well as other factors on students' social skills development in PE classes.

\section{References}

Altman, I., \& Taylor, D. A. (1973). Social Presentation: The Development of Interpersonal Relationships. New York: Holt, Rinehart and Winston.

Anita, E. W., Karen, S. G., \& Mark, J. N. (1977). The Impact of Teacher Behavior, Teacher Sex, and Student Sex upon Student Self-Disclosure. Contemporary Educational Psychology, 2, 124-132.

Bandura, A. (1997). Self-Efficacy: The Exercise of Control. New York: Freeman.

Bennett, G., \& Hastie, P. (1997). A Sport Education Curriculum Model for a Collegiate Physical Activity Course. Journal of Physical Education, Recreation and Dance, 68, 39 44. https://doi.org/10.1080/07303084.1997.10604876

Boyd, M. P., \& Yin, Z. N. (1996). Cognitive-Affective Sources of Sport Enjoyment in Adolescent Sport Participants. Adolescence, 31, 383-395.

Brustad, R. J. (1988). Affective Outcomes in Competitive Youth Sport: The Influence of Interpersonal and Socialization Factors. Journal of Exercise and Sport Psychology, 10, 307-321. https://doi.org/10.1123/jsep.10.3.307

Cai, S. X. (1998). Student Enjoyment of Physical Education Class in Three Teaching Style Environments. Education, 118, 412-421.

Cecchini, J. A., Gonzalez, C., Carmona, A. M., Arruza, J., Escarti, A., \& Balague, G. (2001). The Influence of Physical Education Teacher on Intrinsic Motivation, SelfConfidence, Anxiety, and Pre- and Post-Competition Mood States. European Journal of Sport Science, 1, 1-11. https://doi.org/10.1080/17461390100071407

Danish, S., Petitpas, A., \& Hale, B. (1993). Life Development Interventions with Athletes: Life Skills through Sports. The Counseling Psychologist, 21, 352-385. https://doi.org/10.1177/0011000093213002

Ding, J. D., \& Sugiyama, Y. (2016). Development of a Scale to Assess Chinese College Students' Social Skills in Physical Education Classes. Journal of Heal Science, 38, 11-19.

Dishman, R., \& Dunn, A. (1988). Exercise Adherence in Children and Youth: Implications for Adulthood. In R. Dishman (Ed.), Exercise Adherence: It's Impact on Public Health (pp. 155-200). Champaign, IL: Human Kinetics.

Dolgin, K. G., \& Minowa, N. (1997). Gender Difference in Self-Presentation: A Comparison of the Roles of Flatteringness and Intimacy in Self-Disclosure to Friends. Sex Roles, 36, 371-380. https://doi.org/10.1007/BF02766653

Duncan, R. O., \& Watson, H. B. (1960). Introduction to Physical Education. New York: The Ronald Press Company.

Eldar, E., Morris, D., DaCosta, R., \& Wolf, T. (2006). “Are You Square?” A Game for Developing Self-Control and Social Skills. Strategies, 19, 17-21. https://doi.org/10.1080/08924562.2006.10591200

Enomoto, H. (1987). Self-Disclosure Patterns of College Students and Their Gender Differences in the Patterns. The Japanese Journal of Psychology, 58, 91-97. https://doi.org/10.4992/jjpsy.58.91

Fraser-Thomas, J., \& Cote, J. (2009). Understanding Adolescents' Positive and Negative Developmental Experiences in Sport. The Sport Psychologist, 23, 3-23. 
https://doi.org/10.1123/tsp.23.1.3

González, M. C., Regalado, M. M., \& Guerrero, J. T. (2010). Teaching and Learning Social Values: Experience of Resolution of Conflicts in the Classroom of Physical Education across the Learning of Social Skills. Journal of Human Sport and Exercise, 5, 497-506. https://doi.org/10.4100/jhse.2010.53.20

Gruno, J., \& Gibbons, S. L. (2013). Teaching Teambuilding in Physical Education: Fostering Communication and Cooperation. Physical and Health Education Journal, 79, 6-12.

Hannon, J. C., \& Ratliffe, T. (2004). Cooperative Learning in Physical Education. Strategies, 17, 29-32. https://doi.org/10.1080/08924562.2004.11000362

Hashim, H. A., Grove, J. R., \& Whipp, P. (2008). Testing a Model of Physical Education Enjoyment and Physical Activity among High School Students. Journal of Research in Health, Physical Education, Recreation, Sport \& Dance, 3, 95-99.

Kang, S., \& You, J. (2003). Developing a Challenge Program in School Physical Education. Physical Educator, 60, 20-27.

Laker, A. (2000). Beyond the Boundaries of Physical Education. London, New York: Routledge Falmer.

Maureen, R. W., Nicole, D. B., \& Lindsay, E. K. (2014). Assessing Impact of Physical Activity-Based Youth Development Programs: Validation of the Life Skills Transfer Survey (LSTS). Research Quarterly for Exercise and Sport, 85, 263-278. https://doi.org/10.1080/02701367.2014.931558

Metzler, M. W. (2011). Instructional Models for Physical Education (3rd ed.). Scottsdale, AZ: Holcomb Hathaway.

Pearman, S., \& Valois, R. (1997). The Impact of a Required College Health and Physical Education Course on the Health Status of Alumni. Journal of American College Health, 46, 77-85. https://doi.org/10.1080/07448489709595591

Riggio, R. E. (1986). Assessment of Basic Social Skills. Journal of Personality and Social Psychology, 51, 649-660. https://doi.org/10.1037/0022-3514.51.3.649

Riggio, R. E. (1989). Manual of the Social Skills Inventory. Palo Alto, CA: Consulting Psychologists Press.

Shimamoto, K., \& Ishii, M. (2007). A Study of Influence on Life Skills of Sport Experience in Physical Education Classes in College Students. Japanese Journal of Sport Psychology, 34, 1-11.

Siedentop, D. (1991). Developing Teaching Skills in Physical Education. Mountain View, CA: Mayfield.

Siedentop, D., Hastie, P. A., \& van der Mars, H. (2004). Complete Guide to Sport Education. Champaign, IL: Human Kinetics.

Slentz, T. C., \& Chase, M. A. (2003). Climbing Mount Everest: A New Challenge for Physical Education Adventure Education. Journal of Physical Education, Recreation and Dance, 74, 41-43. https://doi.org/10.1080/07303084.2003.10609201

Smith, B. T., \& Karp, G. G. (1997). The Effect of a Cooperative Learning Unit on the Social Skill Enhancement of Third Grade Physical Education Students. Proceeding from Annual Meeting of the American Educational Research Association, Chicago, IL.

Sugiyama, Y. (2012). Process of Acquisition, Improvement, and Development of Nonverbal Skills through Physical Education (Grant No. 21500564). Research Report, JSPS KAKENHI.

Sugiyama, Y., Shibukura, T., Nishida, T., Ito, T., Sasaki, B., \& Isogai, H. (2010). Development of Scales for Psychosocial Skills in Physical Education and Life Skills. Journal of 
Health Science, 32, 77-84.

Zimmerman, M. (1990). Toward a Theory of Learned Hopefulness: A Structural Model Analysis of Participation and Empowerment. Journal of Research in Personality, 24, 71-86.

Submit or recommend next manuscript to SCIRP and we will provide best service for you:

Accepting pre-submission inquiries through Email, Facebook, LinkedIn, Twitter, etc. A wide selection of journals (inclusive of 9 subjects, more than 200 journals)

Providing 24-hour high-quality service

User-friendly online submission system

Fair and swift peer-review system

Efficient typesetting and proofreading procedure

Display of the result of downloads and visits, as well as the number of cited articles Maximum dissemination of your research work

Submit your manuscript at: http://papersubmission.scirp.org/

Or contact ape@scirp.org 